\title{
$\mathrm{DAC}$ 환경네트워크 7차회의 및 $\mathrm{EPOC}$ (Environment Policy Committee)/ GSP(Global and Structural Policies) 합동회의 결과
}

개발협력에 있어서도 기후변화는 날로 중요한 이슈가 되어가고 있다. 2007년 12월 발리에서 개최된 제13차 당사국 총회에서 제기된 기후변화 관련 개발협력의 새로운 과제들이 2008. 2.26-27일 DAC 환경네트워크 7차 회의 및 $\mathrm{EPOC/GSP}$ 합동회의에서 논의되었다. DAC에서는 동 회의결과를 2008.9월 가나 아크라에서 개최 예정인 원조 효과성에 관한 고위급포럼(HLF)에 반영하기 위한 방안 을 모색한바, 앞으로 기후변화의 개발협력과의 연계는 매우 강화될 전망인바, 기후변화를 포함한 환경 분야에 대한 $\mathrm{ODA}$ 활용과 관련한 개발원조 정책이 미흡한 우리나라로서는 개발협력에 기후변화를 포 함한 환경문제를 하루속히 대응해야 할 필요가 있다고 하겠다. [ 정리 : 정책연구실 ]

\section{I . 핵심요지}

- (기후변화와 개발협력) $\mathrm{OECD}-\mathrm{DAC}$ 는 개발과 환경의 연계 강화 및 개발협력에 기후변화 적 응을 통합하기 위한 노력의 일환으로 금년 HLM에서 "Statement of Progress on the Mainstreaming of Climate Change Adaptation into Development $\mathrm{Co}^{-}$ operation"을 채택할 예정임.
- 금번 회의에서는 2007.12 월 발리 회의 결과 온실가스 감축(mitigation), 기후변화 적응 (adaptation), 기술개발 및 이전, 재원조달 문제와 관련하여 개발협력에 새로운 과제들 이 제기됨에 따라 이에 대한 대응 방안 모색 에 중점을 둔 논의가 이루어짐.

- 특히, 다수 참가국들이 기후변화 적응 및 온 실가스 감축을 위한 재원마련에 $\mathrm{ODA}$ 활용 방안 모색이 가장 중요한 문제임을 지적하 
였으며, 기존 ODA 예산내에서의 추가 배분 은 수원국의 원조 수요와의 불일치 문제 등 을 야기할 수 있다는 점에서 추가적 (additional), 혁신적(innovative) 재원 마련 의 필요성을 제기함.

- (전략적 환경평가 활용) 개발원조 이행에 환경 적 요소를 통합하기 위한 방안의 하나로 프로 그램/정책 차원에서 환경적 요소 반영을 평가 하는 전략적 환경평가(SEA, Strategic Environment Assessment)의 활용 필요성이 강조됨.

- 그러나 일본 등 일부 공여국은 이를 활용하 기 위해서는 보다 많은 성공사례(good practices) 제시와 가이드라인 제공이 필요 하다고 지적함.

- (아크라 회의에의 반영) 다수 참가국들은 기후 변화 이슈가 개발협력 분야에서도 최우선 해결 과제라는 점에 동의하고, 아크라 고위급회의 의제(AAA, Accra Action Agenda)에 적극 반 영되어야 함을 강조함.

- (제 2 차 환경개발장관회의 개최 여부) 일본, 스 웨덴 등은 개발과 환경의 연계 강화 모멘텀 유 지를 위해 2009년 제2차 환경개발장관 회의 개최에 적극적 지지를 표한 반면, 미국 등 일부 참가국은 개발과 기후변화와 관련 회의가 다수
개최될 예정이며 정치적 상황 변화를 예측하기 어려움을 근거로 유보적 입장을 표명함에 따라 향후 개최여부를 재논의 하기로 함.

\section{II. 관찰 및 평가}

- (기후변화 관련 ODA 활용 방안 검토) 우리나 라는 기후변화를 포함한 환경 분야 ODA 활용 과 관련한 개발원조 정책 및 구체적 이행 방안 이 아직 미흡한바, 이에 대한 전반적인 검토와 개선방안 모색이 필요할 것으로 보임.

- 특히, 기후변화 대응을 위한 국제적 논의가 활발히 진행될 예정(G8 개발장관 회의, 아 크라 회의, 환경개발장관 회의 등)이고 우리 나라의 기여에 대한 요구도 증대할 가능성 이 높은바, $\mathrm{ODA}$ 활용 또는 추가적 재원 조 달 방안도 검토해볼 필요가 있음.

- (전략적 환경평가 활용 가능성 검토) 다수 회원 국들이 $\mathrm{SEA}$ 활용의 중요성과 적용 확대 필요 성을 강조하고 있고, SEA가 환경적 요소를 개 발원조 정책에 통합하는 구체적 방법론을 제시 하고 있는바, 이에 대한 검토를 통해 우리 정책 에의 반영 노력이 필요할 것으로 보임.

- 다만, SEA가 "best practices" 발굴 등 발 전단계에 있고, 일본 등 일부 공여국도 $\mathrm{SEA}$ 
적용에 신중한 입장을 보이고 있는 것으로 파악되는 바, 단계적 도입방안을 검토해 볼 필요가 있음.

- (원조 효과에 관한 아크라 회의 준비) 현재 ENVIRONET을 비롯한 DAC 산하 작업반들 은 각각 아크라 회의 준비를 위한 논의를 진행 중인바, 주요 논의 동향을 파악하고 원조효과 작업반 $(\mathrm{EFF})$ 을 중심으로 이루어지고 있는 준 비 작업에 적극 참여가 요구됨.

\section{III. 상세 논의 내용}

\section{ENVIRONET 제7차 회의 결과}

- (기후변화와 개발협력) $\mathrm{DAC}$ 는 기후변화 문제 를 최우선과제중의 하나로 보고 있으며, 개발 협력에 기후변화 적응을 통합하기위한 노력을 지속적으로 전개해옴.

- 2006년 환경개발장관회의에서 채택된 '개발 협력에 기후변화 적응 통합을 위한 선언'과 더불어 2007.12월 DAC-HLM에서 제안된 "Statement of Progress on the Mainstreaming of Climate Change Adaptation into Development Cooperation"을 2008.5월 HLM에서 공식 채 택할 예정이며, 6월 홋카이도 G8 회의 및 9
월 아크라 회의에서도 발표할 계획임.

- 금번 회의에서는 2007.12월 발리 회의 결과 온실가스 감축(mitigation), 기후변화 적응 (adaptation), 기술이전 및 재원조달 문제와 관련하여 개발협력에 새로운 과제들이 제기 됨에 따라 이에 대한 대응 방안 모색에 중점 을 둔 논의가 이루어짐.

-(적응과 감축) 발리 회의 결과 선진국뿐만 이 아니라 개도국을 포함한 모든 국가의 온 실가스 감축(mitigation) 노력 필요성이 강 조됨에 따라, 개도국의 기후변화 적응 (adaptation) 지원과 더불어 개도국의 온실 가스 감축 노력 참여를 촉진하기 위한 기술 지원 및 재정지원 문제가 부각되고 있음.

- (재원조달을 위한 $\mathrm{ODA}$ 활용) 다수 참가국 들은 기후변화 적응 및 온실가스 감축을 위 한 재원마련과 관련한 $\mathrm{ODA}$ 활용 가능성과 활용 방안 모색이 가장 중요한 문제임을 지 적함. 특히, 기후변화 적응의 주류화 (mainstreaming of climate change adaptation)와 관련하여 기존 $\mathrm{ODA}$ 예산 내 에서의 추가 배분은 수원국의 원조 수요와 의 불일치 문제 등을 야기할 수 있다는 점에 서 추가적(additional), 혁신적(innovative) 재원 마련의 필요성이 제기됨.

-(에너지 분야와 연계) 개도국의 온실가스 감축 노력은 특히 에너지 분야에서 효과적 
으로 이루어질 수 있으며, 재생가능 에너지 (renewable energy) 개발 및 에너지 효율 성(energy efficiency) 증대를 위한 지원 필 요성이 강조됨.

- (기타 이슈) 기후변화 관련 개도국의 능력 배양(capacity building)을 위한 기술이전 과 $\mathrm{CDM}($ Clean Development Mechanism) 활용 및 벌목(deforestration) 문제 등을 논 의함.

- (전략적 환경평가 활용 촉구) 개발원조 이행에 환경적 요소를 통합하기 위한 방안의 하나로 전 략 적 환 경 평 가 $(\mathrm{SEA}$, Strategic Environment Assessment)의 활용 필요성이 강조되었으며, 다수 참가국들은 기후변화와 관 련하여서도 $\mathrm{SEA}$ 의 활용 방안 개발 필요성을 제기함.

- SEA는 개별 프로젝트 수준에서 이루어지는 기존의 환경영향평가와는 달리 프로그램/정 책 수준에서도 환경적 요소를 고려하여 개발 원조를 이행하는 것을 목적으로 함.

- SIDA, CIDA, 독일, 덴마크 등 다수 선진공 여국들 및 개발원조 기관들은 원조 이행에 있어서 $\mathrm{SEA}$ 를 적극 반영하고 있으나, 일본 등 일부 공여국은 이를 활용하기 위해서는 보다 많은 성공사례(good practices) 제시와 가이드라인 제공이 필요하다고 지적함.
- (아크라 회의에의 반영) 2008.9월 가나 아크라 에서 개최 예정인 원조 효과성에 관한 고위급 포럼(HLF)의 기본 회의 구성안 및 회의 준비 일정 소개와 함께, 동회의에 기후변화를 포함 하는 환경관련 이슈를 반영하기 위한 방안을 논의함.

- 다수 참가국들은 기후변화 이슈가 개발협력 분야에서도 최우선 해결과제라는 점에 의견 을 같이하고, 실제 원조이행에 중점을 둔 라 운드테이블 논의뿐만이 아니라 고위급회의 의제(AAA, Accra Action Agenda)에도 적 극 반영되어야 함을 강조함.

- 아울러 원조 효과성에 관한 파리 선언은 원 조조화(harmonization)와 관련하여 공동의 환경평가 방안 마련 필요성을 규정하고 있는 바, 아크라 회의를 통해 $\mathrm{SEA}$ 의 중요성과 활 용 확대를 강조할 필요성이 제기됨.

\section{- (기타 이슈)}

- 환경 $\mathrm{ODA}$ 에 대한 분류기준은 $\mathrm{DAC}$ 차원에 서도 명확하지 않으며, $\mathrm{DAC}$ 통계작업반은 "Rio Marker"(생물다양성, 기후변화, 사막화 관련 $\mathrm{ODA})$ 에 대한 통계 보고를 3년간('04'06) 시범적으로 실시하고 공식도입을 추진 하고 있으나, 영국 등 7 개 $\mathrm{DAC}$ 회원국의 미 참여로 인하여 공식 분류기준으로의 도입 여 
부는 추가적 논의를 통해 결정할 예정임.

- 회원국들의 보고에 기반하여 ENVIRONET 이 제공하고 있는 환경관련 원조활동조사 (survey of agencies' country-level activities on environment and development)에 대해 다수 참가국들은 설문 조사의 유용성은 인정하지만, 실제 동조사를 활용하기 위한 방안 마련이 필요함을 언급함.

\section{ENVIRONET-EPOC/WPGSP 제3차 합 동회의 결과}

- (작업반 활동 검토) $\mathrm{EPOC}$ 산하 3개 작업반(기 후변화 적응과 개발협력 통합, 자연자원과 환 경 관리 능력 배양, 수자원 공급과 위생을 위한 재원조달)은 2006 년 환경개발장관회의 이후 활동 결과를 보고함.

- 특히, 기후변화 적응과 개발협력 통합을 위 한 작업반은 "기후변화 적응과 개발협력 통 합 가이드라인 초안" (The First Draft Guidance Document on Integrating Climate Change Adaptation into Development Cooperation)을 제시한바, 다 수 참가국들은 동 초안의 유용성을 높이 평 가하였으며, 향후 온실가스 감축(mitigation) 과 관련한 작업도 진행하기를 제안함.
- 수자원 공급과 위생 관련 재원조달 작업반이 제시한 재원조달 전략 개요 초안(Draft Outline of the Report on Financing Strategies for Water Supply and Sanitation)에는 우리나라 사례연구가 포함 되어 있음.

\section{- (제2차 환경개발장관 회의 개최 여부)}

- 일본, 스웨덴, $\mathrm{EC}$ 등은 개발과 환경의 연계 강화 모멘텀 유지를 위한 2009년 제2차 환 경개발장관 회의 개최에 적극적 지지를 표 명함.

- 반면, 미국은 원칙적으로는 환경개발장관 회 의 개최에 찬성하지만 기후변화와 개발 관련 회의가 다수 개최될 예정이며 정치적 상황 변화를 예측하기 어려움을 근거로 유보적 입 장을 표하였으며, 네덜란드, 오스트리아 등 은 장관 참석을 촉구하기 위해서는 우선 아 젠다 확정이 필요함을 언급함.

- 이에 따라, 사무국 측은 "soft agenda proposal"을 우선 제시하고 $\mathrm{EPOC}$ 과 DAC 의 고위급 회담 일정 조정을 통해 2009년 제 2 차 환경개발장관 회의 개최를 추진하겠다 고 함.

[자료: 주오이시디대표부] 